\title{
IMPLEMENTASI SISTEM PENDUKUNG KEPUTUSAN PENENTUAN PENERIMA POTONGAN UKT BAGI MAHASISWA YANG TERDAMPAK PANDEMI COVID-19 MENGGUNAKAN METODE TOPSIS
}

\author{
Winny Purbaratri ${ }^{1}$, Roy Mubarak ${ }^{2}$ \\ ${ }^{1}$ Program Studi Teknik Informatika Perbanas Institute, ${ }^{2}$ Teknik Informatika Universitas Pamulang \\ e-mail: winny.purbaratri@ perbanas.id ${ }^{1}$,roy.dosen@gmail.com ${ }^{2}$
}

\begin{abstract}
The Covid-19 pandemic has caused many new problems, including the community's economy, which has a major influence on the economy in the field of education. For students who are still financed by their parents, many end up not paying the Single Tuition Fee due to the condition of their parents who are not working or have their salaries cut during the Covid-19 pandemic. Decision Support System for Determining UKT Deduction Recipients for Students Affected by the Covid-19 Pandemic Using the Topsis Method. Can be a solution for universities to determine recipients of rocks from the Ministry of Education and Culture. Methodology This research was conducted with a 2-method approach, namely field studies conducted by interviewing the student affairs department who administers UKT assistance programs at universities and library studies to collect information related to decision support systems using the TOPSIS method. The results of the study in the form of a Decision Support System application using the Topsis Method helped accelerate the Higher Education Party to get a list of names of students who would receive UKT assistance. This web-based system is built with the PHP 7.4 programming language with the Bootstrap framework and MySQL database.
\end{abstract}

Keywords - System, Decision Support System, UKT, Covid-19, Topsis

\begin{abstract}
ABSTRAK
Pandemi covid-19 menimbulkan banyak permasalahan baru diantaranya ekonomi masyarakat berpengaruh besar pada roda perekonomian dibidang usaha pendidikan. Bagi mahasiswa yang masih dibiayai orang tua, banyak yang mengalami kendala dalam pembayaran uang kuliah di karenakan kondisi orang tua yang tidak bekerja atau di potong gajinya selama pandemi covid-19. Sistem Pendukung Keputusan Penentuan Penerima Potongan Uang Kuliah Tunggal bagi mahasiswa yang terdampak pandemi covid-19 menggunakan metode Topsis. Dapat menjadi solusi bagi perguruan tinggi untuk mementukan penerima bantuan dari Kemendikbud. Metodologi Penelitian ini dilakukan dengan pendekatan 2 (dua) metode, yaitu studi lapangan yang dilakukan dengan cara wawancara dengan bagian kemahasiswaan yang mengurus program bantuan Uang Kuliah Tunggal di perguruan tinggi dan studi pustaka untuk mengumpulkan informasi terkait sistem pendukung keputusan yang menggunakan metode Topsis. Hasil penelitian berupa aplikasi Sistem Pendukung Keputusan menggunakan Metode Topsis membantu mempercepat Pihak Perguruan Tinggi untuk mendapatkan daftara nama mahasiswa yang akan mendapatkan bantuan Uang Kuliah Tunggal tersebut. Sistem berbasis web ini
\end{abstract}


dibagun dengan bahasa pemrograman PHP 7.4 dengan framework Bootstrap dan basis data MySQL.

Kata Kunci-Sistem, Sistem Pendukung Keputusan, UKT, Covid-19, Topsis

\section{Pendahuluan}

Covid-19 tidak hanya menyerang imunitas manusia, tetapi juga menerang kondisi ekonomi suatu bangsa. Dengan adanya pandemic covid-19 banyak karyawan swasta yang dirumahkan. Karena penerapan Pembatasan Sosial Berskala Besar.

Secara tidak langsung pandemic covid-19 juga menyerang kondisi ekonomi orang tua mahasiswa yang berkuliah diperguruan tinggi atau mahasiswa karyawan yang mengalami pengurangan jam kerja dan pemberhentian kerja baik sementara atau pun selamanaya.

Kemendikbud juga berusaha mengamankan stabilitas dari Perguruan Tinggi Swasta. Dengan mengeluarkan program Pemberian Uang Kuliah Tunggal. Permendikbud No. 10 Tahun 2020 tentang Program Indonesia Pintar (PIP), Pemerintah telah berkomitmen untuk memberikan bantuan Pendidikan melalui PIP. PIP diperuntukkan bagi mahasiswa yang diterima di perguruan tinggi termasuk penyandang disabilitas dengan prioritas sasaran mahasiswa pemegang KIP, mahasiswa dari keluarga miskin/rentan miskin, mahasiswa dari panti sosial/panti asuhan, dan/atau mahasiswa dalam kondisi dengan pertimbangan khusus [1].

Dengan adanya program pemberian UKT (Uang Kuliah Tunggal) dari pemerintah, disambut baik oleh mahasiswa di Perguruan Tinggi Swasta. Pada saat periode pengajuan data diri mahasiswa agar dapat diberikan potongan UKT. Menjadi masalah bagi Perguruan Tinggi, karena data pengajuan diri mahasiswa tidak berbanding lurus dengan jumlah kuota yang diberikan oleh pemerintah, sehingga pihak Perguruan Tinggi harus melakukan seleksi penerima bantuan potongan UKT (Uang Kuliah Tunggal). Untuk menghindari keputusan yang tidak subyektif dan agar penerima beasiswa memang dipilih berdasarkan kriteria yang telah ditentukan berdasarkan skala prioritas oleh Pihak Kampus.

Berdasarkan latar belakang masalah diatas maka peneliti akan membuat Sistem Pendukung Keputusan Penentuan Penerima Potongan UKT Bagi Mahasiswa Yang Terdampak Pandemi Covid-19 Menggunakan Metode Topsis. 
Sistem pendukung keputusan menggabungkan sumber daya intelektual individu dengan kemampuan komputer untuk meningkatkan kualitas keputusan. Ini adalah sebuah sistem pendukung berbasis komputer untuk pengambil keputusan manajemen yang menangani dengan masalah semi terstruktur. [2]

TOPSIS (for the Technique for Order Preference by Similarity to Ideal Solution) dibuat oleh Yo on and Hwang [1980] sebagai alternatif dari metode ELECTRE dan dapat dianggap sebagai salah satu varian metode yang paling banyak diterima. Konsep dasar dari metode ini adalah bahwa alternatif yang dipilih harus memiliki jarak terpendek dari solusi ideal dan jarak terjauh dari solusi negatif-ideal dalam beberapa pengertian geometris. [3]

Berikut ini langkah-langkah yang dilakukan oleh metode TOPSIS:

1. Membuat decision matrix untuk alternative

$$
\mathrm{D}=\left[\begin{array}{ccc}
x 11 & \cdots & x 1 n \\
\vdots & \ddots & \vdots \\
x m 1 & \cdots & x m n
\end{array}\right]
$$

\section{Gambar 1. Decision Matrix}

2. Hitungan normalisasi decision matrix

$$
N=\frac{\text { Data }}{\text { Akar hasil pangkat per kriteria }}
$$

Gambar 2. Normalize Decision Matrix

3. Menentukan solusi ideal positif $\mathrm{V}+$ dan solusi ideal negative $\mathrm{V}$ -
$D x+=$

$\sqrt{(A x C 1-Y 1+)^{2}+(A x C 1-Y 1+)^{2}}+$ $\cdots+(A x C n-Y n+)^{2}$

$D x+=$

$\sqrt{(A x C 1-Y 1-)^{2}+(A x C 1-Y 1-)^{2}}+$ $\cdots+(A x C n-Y n-)^{2}$

4. Menentukan nilai preferensi untuk setiap alternative.

$$
V x-=\frac{D x-}{(D x-)+(D x+)}
$$

\section{METODE PENELITIAN}

\subsection{Tahap Metode Penelitian}

Penelitian yang digunakan adalah penelitian terapan (Applied Research). Dalam penelitian ini, sampel data yang digunakan yaitu data mahasiswa. Pengumpulan data dilakukan metode pengumpulan data primer maupun sekunder. Pada Metode Pengumpulan data primer Yaitu dengan cara melakukan pengumpulan data langsung ke sumber data yang dimiliki Perguruan Tinggi. juga pengumpulan data dilakukan dengan metode observasi, wawancara dan kuesioner untuk metode pengumpuan data sekunder dilakukan dengan cara membaca, mengamati dan mempelajari data dari sumber yang berhubungan dengan penelitian ini. [4] 

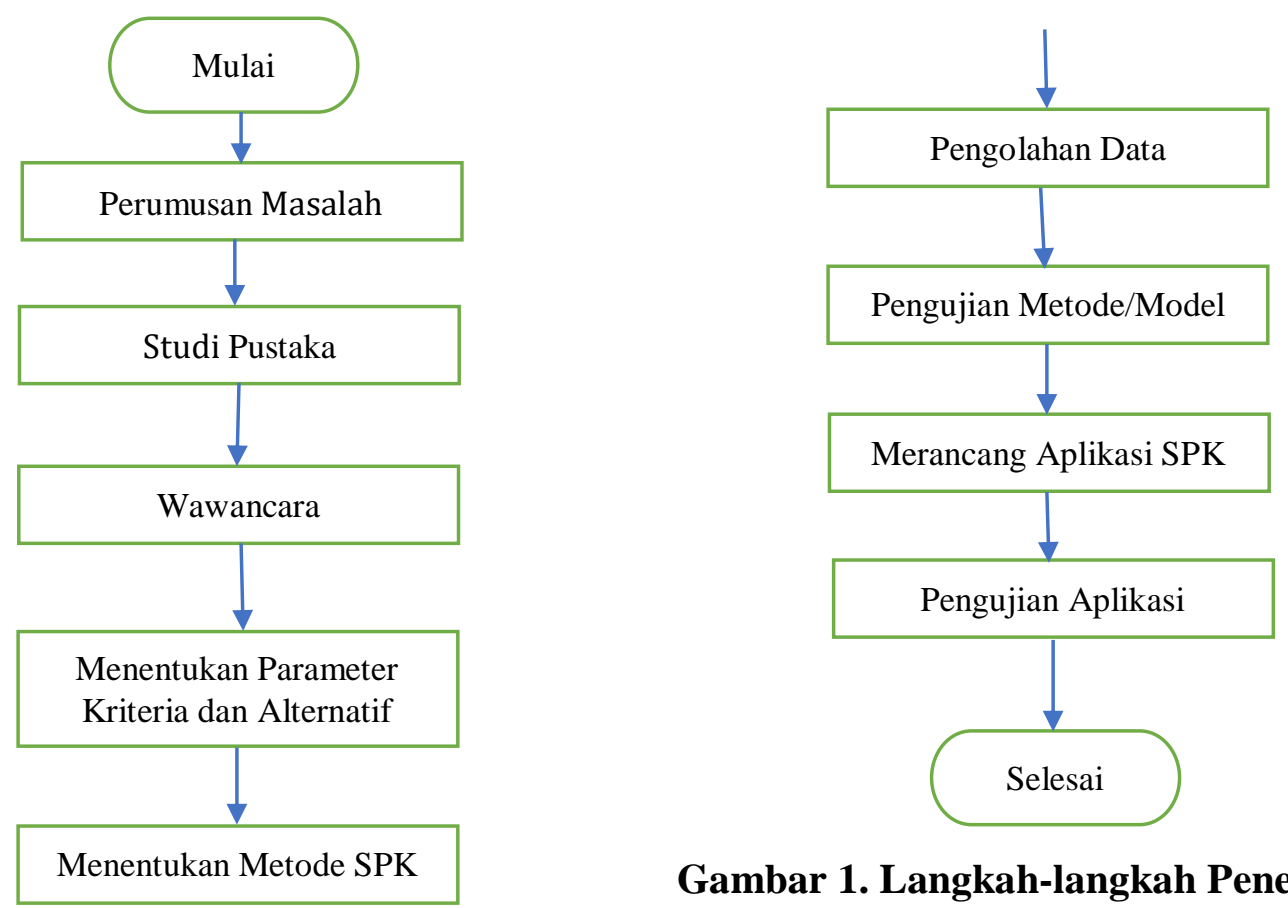

Gambar 1. Langkah-langkah Penelitian

\subsection{Tinjauan Penelitian}

Tabel 1. Tinjauan Penelitian

\begin{tabular}{|c|c|c|c|c|}
\hline No & $\begin{array}{c}\text { Nama dan } \\
\text { Tahun } \\
\text { Penelitian } \\
\end{array}$ & Judul dan Lokasi Penelitian & Metode & Hasil Penelitian \\
\hline 1 & $\begin{array}{l}\text { Benyamin } \\
\text { Imanuel } \\
\text { Libing, } \\
\text { Dony M. } \\
\text { Sihotang, } \\
\text { Meiton } \\
\text { Boru. } \\
(2019)\end{array}$ & $\begin{array}{l}\text { Sistem Pendukung Keputusan } \\
\text { Penentuan Uang Kuliah Tunggal } \\
\text { Kepada Mahasiswa Baru di } \\
\text { Universitas Nusa Cendana } \\
\text { Menggunakan Metode TOPSIS }\end{array}$ & TOPSIS & $\begin{array}{l}\text { Sistem akan menyeleksi setiap alternatif } \\
\text { menggunakan lima kriteria yaitu pendapatan } \\
\text { orang tua, rekening air dan listrik, aset, } \\
\text { jumlah tanggungan dan pekerjaan. Hasil dari } \\
\text { pengujian senstifitas perubahan bobot, yang } \\
\text { paling besar yaitu pada rekening air dan } \\
\text { listrik dengan } 91.66 \% \text { dan yang paling } \\
\text { sedikit } \\
\text { yaitu pada pekerjaan dengan } 35 \% \text {. }\end{array}$ \\
\hline 2 & $\begin{array}{l}\text { Tri Hasanah } \\
\text { Bimastari } \\
\text { Aviani dan } \\
\text { Asep Toyib } \\
\text { Hidayat } \\
\text { (2020) }\end{array}$ & $\begin{array}{l}\text { Sistem Pendukung Keputusan } \\
\text { Seleksi Pemberian Uang Kuliah } \\
\text { Tunggal Menerapkan Metode } \\
\text { WASPAS }\end{array}$ & WASPAS & $\begin{array}{l}\text { Metode WASPAS dapat digunakan untuk } \\
\text { menseleksi Mahasiswa penerima Uang } \\
\text { Kuliah Tunggal (UKT) dengan kriteria- } \\
\text { kriteria yang telah ditentukan. Hasil yang } \\
\text { diperoleh dari penelitian ini adalah terdapat } \\
\text { satu mahasiswa dengan nilai tertinggi yaitu } \\
\text { 10,88 menduduki peringkat satu, dengan } \\
\text { demikian mahasiswa tersebut berhak } \\
\text { meneriam Uang Kuliah Tunggal (UKT) }\end{array}$ \\
\hline 3 & $\begin{array}{l}\text { Syaiful } \\
\text { Rokhman, } \\
\text { Imam } \\
\text { Fahrur Rozi } \\
\text { dan Rosa } \\
\text { Andrie } \\
\text { Asmara } \\
(2017)\end{array}$ & $\begin{array}{l}\text { PENGEMBANGAN SISTEM } \\
\text { PENUNJANG KEPUTUSAN } \\
\text { PENENTUAN } \\
\text { UKT MAHASISWA DENGAN } \\
\text { MENGGUNAKAN METODE } \\
\text { MOORA } \\
\text { STUDI KASUS POLITEKNIK } \\
\text { NEGERI MALANG }\end{array}$ & MOORA & $\begin{array}{l}\text { Sistem Penunjang Keputusan (SPK) } \\
\text { penentuan Uang Kuliah } \\
\text { Tunggal (UKT) Mahasiswa Politeknik } \\
\text { Negeri Malang dengan menggunakan } \\
\text { metode MOORA dapat memberikan } \\
\text { alternatif terbaik dalam penentuan uang } \\
\text { kuliah tunggal berdasarkan kemampuan } \\
\text { ekonomi mahasiswa. }\end{array}$ \\
\hline
\end{tabular}




\subsection{Model Penentuan Penerima Potongan UKT dengan metode TOPSIS}

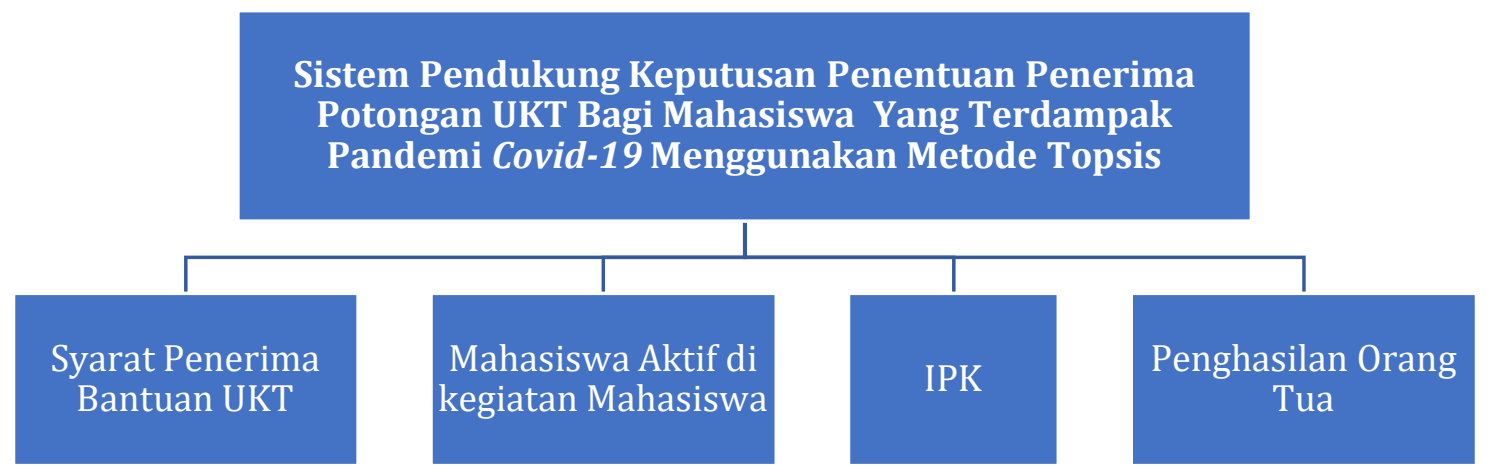

Gambar 2. Kriteria yang digunakan untuk Sistem Pendukung Keputusan Penerima Potongan UKT

\subsection{Kriteria Penentuan Penerima Potongan Uang Kuliah Tunggal (UKT)}

Berdasarkan ketentuan yang ditetapkan oleh kemendikbud, ditambah persyaratan dari Perguruan Tinggi. Jika jumlah pengajuan Penerima Potongan Uang Kuliah Tunggal melebihi kuota yang diberikan oleh pihak kemendikbud.

\subsection{Pengembangan Sistem}

Sistem Pendukung Keputusan menggunakan Metode TOPSIS, melalui beberapa tahap perhitungan diatas. Maka peneliti dapat merancang sistem pendukung keputusan menggunakan metode Topsis. Langkah selanjutnya adalah Perancangan Sistem dengan tahapan Perancangan Diagram Use Case, serta perancangan perancangan relasi antar tabel berupa ERD (Entity Relationship Diagram).

Untuk perangkat hardware yang di gunakan oleh peneliti dalam perancangan Sistem Pendukung Keputusan Penentuan Penerima Potongan UKT adalah: notebook Dell Latitude 7280 dengan software : Sistem Operasi Windows 10, tools Visual Studio Code, Web Server berbasis Apace ( XАMPP PHP Versi 7.4), Untuk perancangan beberapa diagram yang dibutuhkan dan MS. Visio versi 2019.

\subsection{Desain Sistem}

1. DFD (Data Flow Diagram)

Pembahasan proses bisnis dari Sistem Pendukung Keputusan Penentuan Penerima Potongan UKT adalah sebagai berikut: 


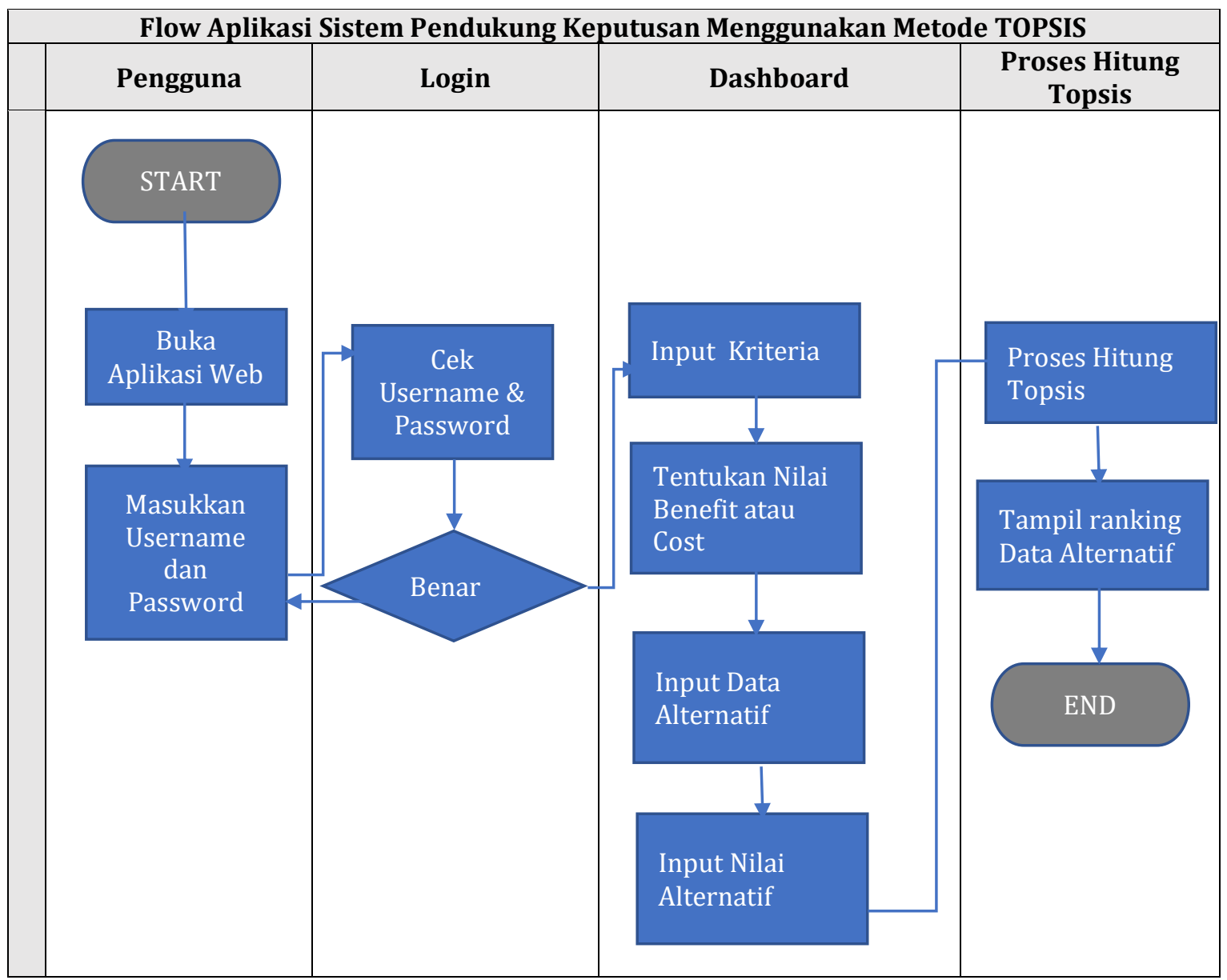

\section{Gambar 3. Proses Bisnis}

Penjelasan dari alur proses bisnis diatas adalah sebagai berikut:

a. Operator aplikasi melakukan akses ke Sistem Pendukung Keputusan Penentuan Penerima Potongan UKT dengan menginput: username dan password.

b. Bila username dan password benar, maka proses selanjutnya adalah akses pada menu dashboard.

c. Dari menu dashboard, kemudian operator dapat memilih menu Kriteria. d. Langkah berikutnya operator menentukan nilai cost atau benefit dari kriteria tersebut.

e. Selanjutnya Operator memasukan data alternatif, yaitu mahasiswa peserta pengajuan Penerimaan Potongan UKT .

f. Jika data sudah di masukan semua. Maka operator memilih menu hitung yang sudah dimasukan rumus dari metode Topsis

g. Dashboard akan menampilkan perangkingan dari peserta 
pengajuan pemotongan biaya UKT.

\section{Use Case Diagram}

Berikut ini adalah diagram use case yang merupakan inti dari aplikasi Sistem Pendukung Keputusan Penentuan Penerima Potongan UKT, yaitu: [5]

a. Diagram Use Case untuk Actor administrator

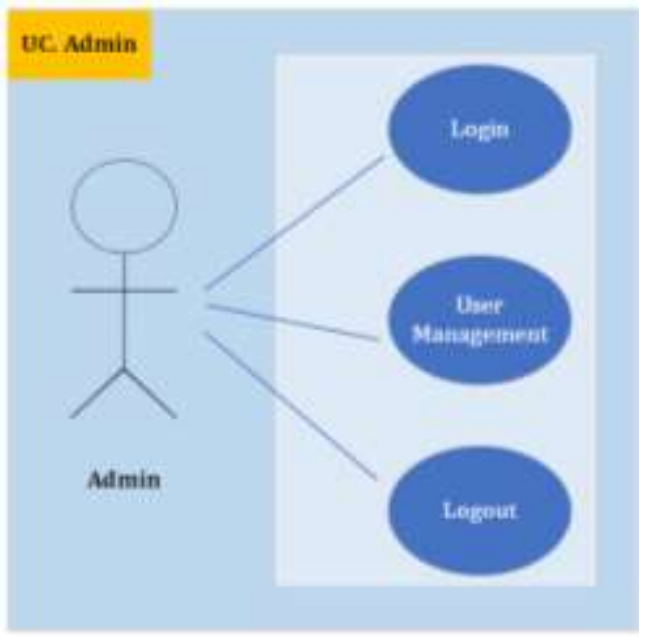

Gambar 4. Diagram Use Case Adminsitrator

b. Diagram Use Case untuk Actor : Operator

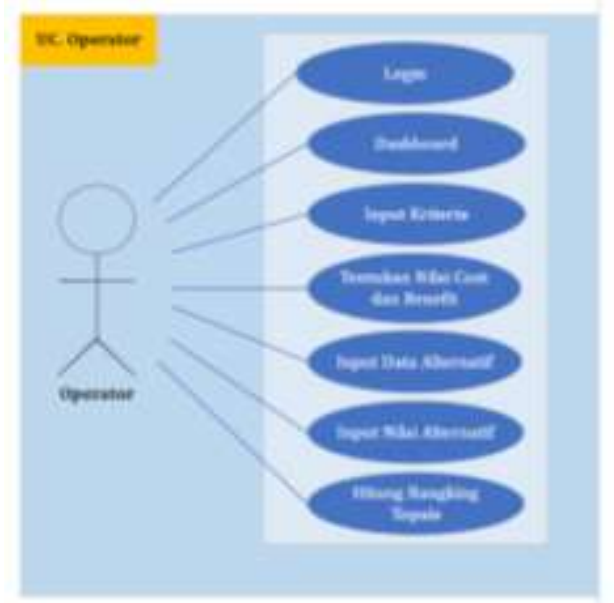

Gambar 5. Diagram Use Case Operator

\section{ERD (Entity Relationship Diagram)}

ERD merupakan diagram yang menunjukan informasi dalam bentuk basis data yang dibuat, kemudian disimpan dan digunakan dalam sistem bisnis. Tabel dalam ERD saling memiliki keterikatan satu sama lainnya sehingga membentuk suatu hubungan relasi satu sama lain. Berikut adalah ERD dari Sistem Pendukung Keputusan Penentuan Penerima Potongan UKT Menggunakan Metode TOPSIS. [6]

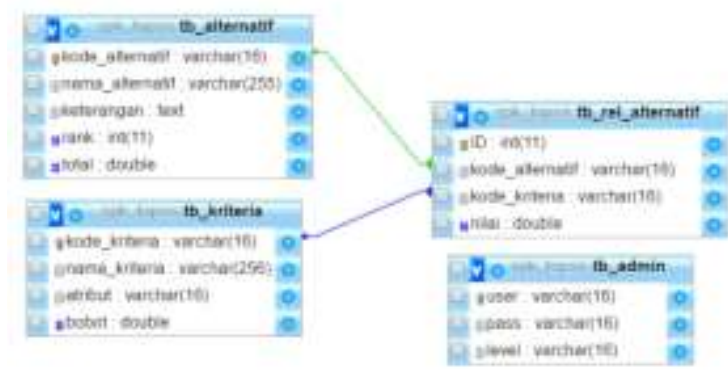

Gambar 6. Entity Relationship Diagram Sistem Pendukung Keputusan Penentuan Penerima Potongan UKT Menggunakan Metode TOPSIS

\section{Hasil dan PeMbahasan}

\subsection{Hasil}

1. Basis Data

Basis data yang dipergunakan untuk Sistem Pendukung Keputusan Penentuan Penerima Potongan UKT Menggunakan Metode TOPSIS ini adalah mempergunakan MySQL. Aplikasi mempergunakan 4 tabel.[7] 


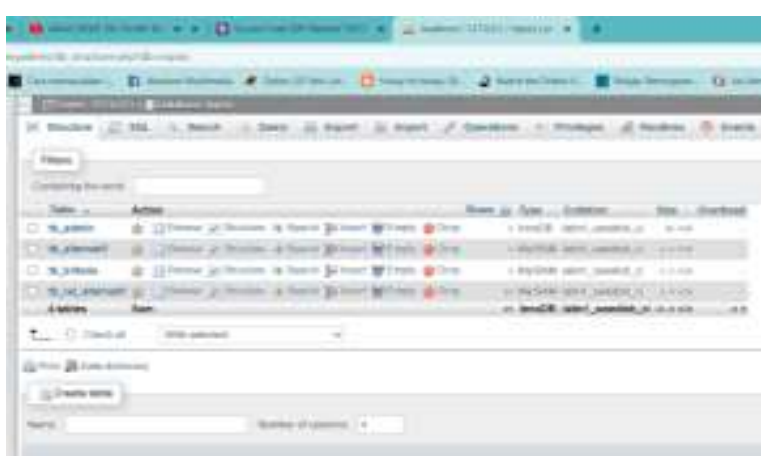

Gambar 7. Database

2. Laman Aplikasi

Hasil dari Sistem Pendukung Keputusan Penentuan Penerima Potongan UKT Menggunakan Metode TOPSIS adalah sebagai berikut:[8][9]
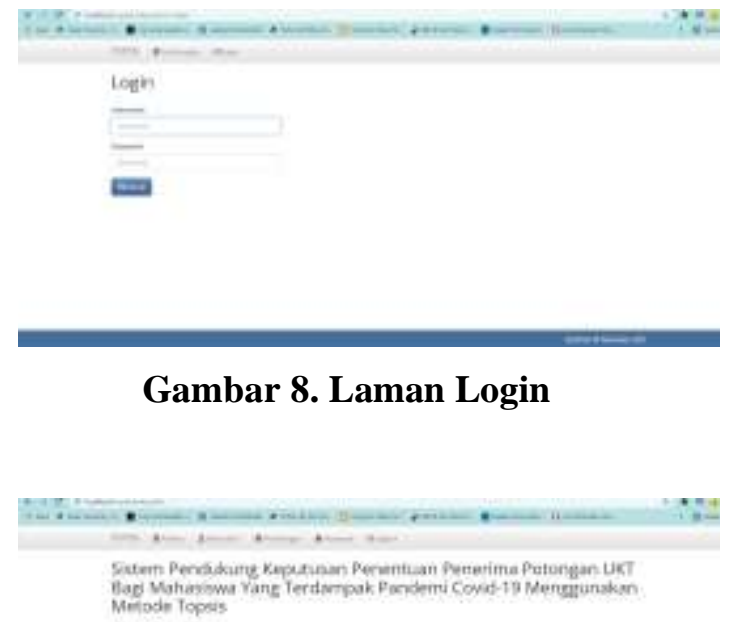

Gambar 9. Laman Dashboard

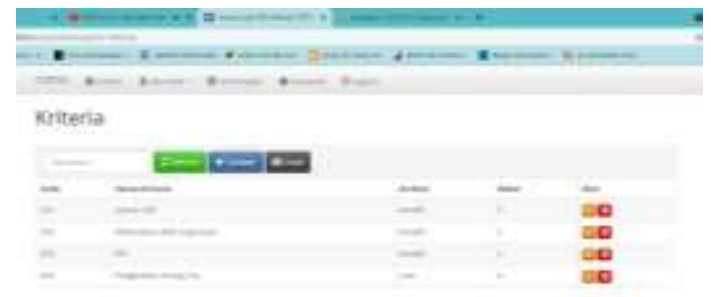

Gambar 10. Laman Kriteria

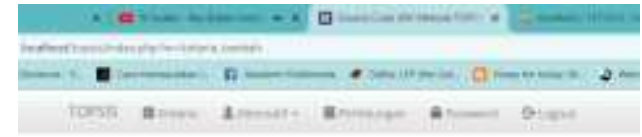

Tambah Kriteria

$\infty$ -
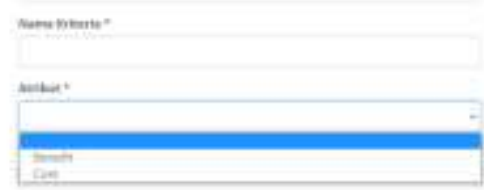

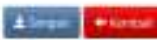

\section{Gambar 11. Laman Pentuan Cost} dan Benefit

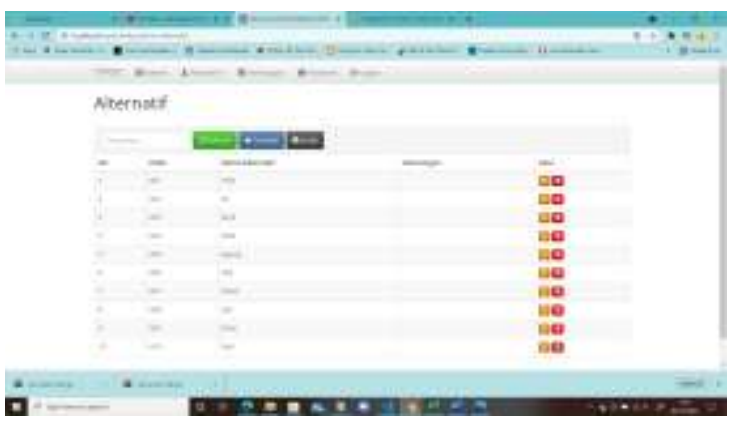

Gambar 12. Laman Input Data Alternatif

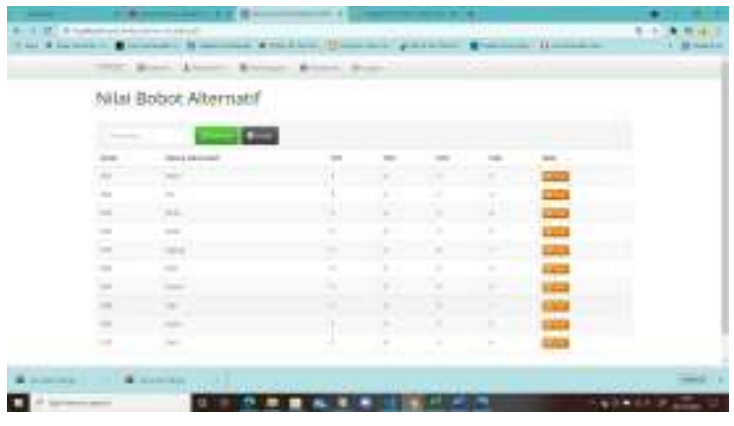

Gambar 13. Laman Nilai Alternatif

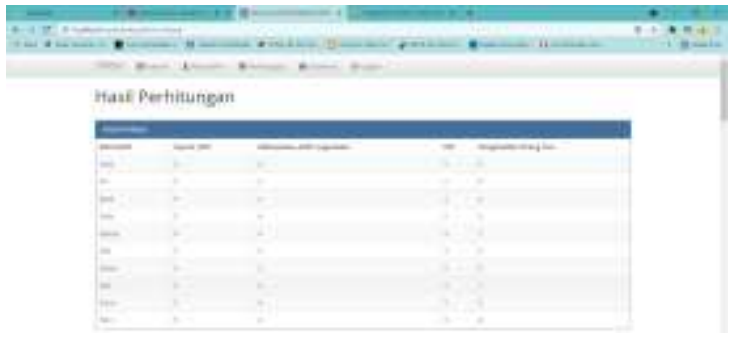




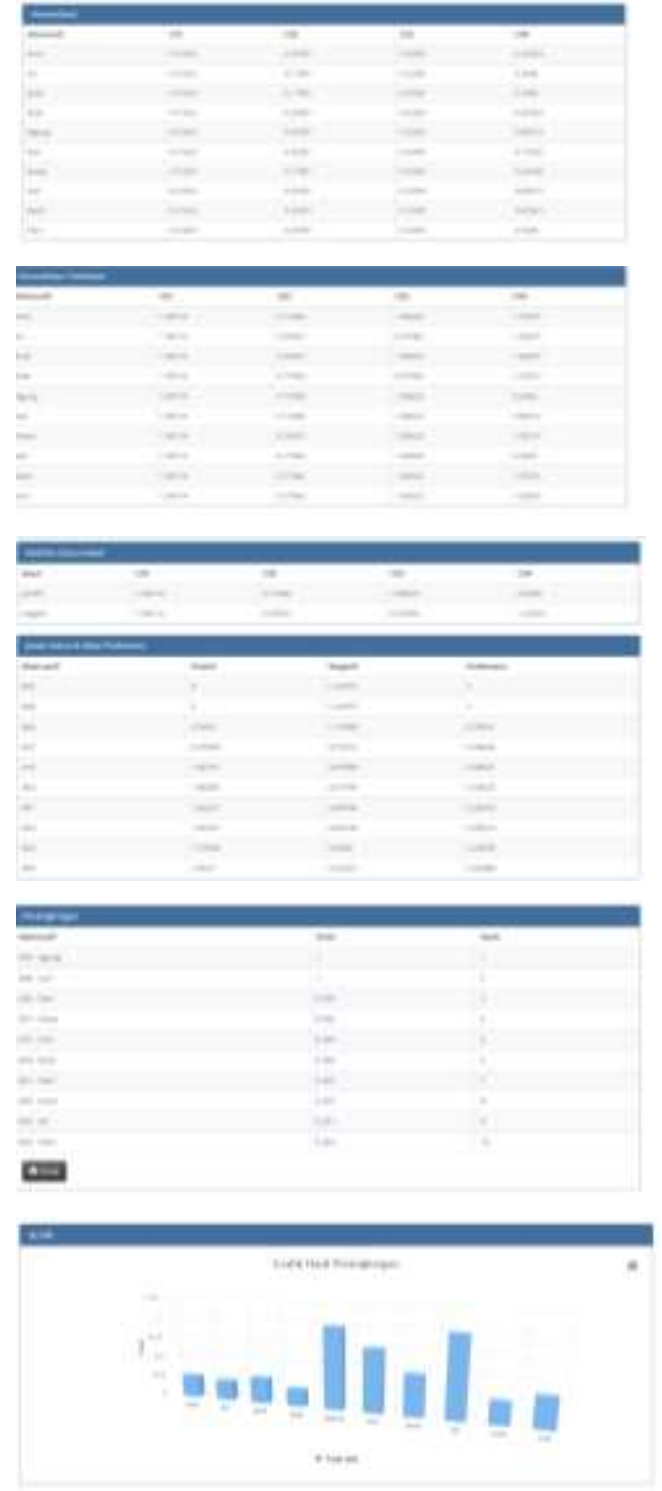

Gambar 14. Laman Perhitungan Topsis

3. Fitur Aplikasi

Adapun Fitur Sistem Pendukung Keputusan Penentuan Penerima Potongan UKT Menggunakan Metode TOPSIS adalah sebagai berikut:

- Dashboar Aplikasi

- Input Kriteria

- Penentuan Cost dan Benefit

- Input Data Alternatif
- Input Nilai Alternatif

- Manajemen pengguna

4. Kelebihan dan Kekurangan Sistem Pendukung Keputusan Penentuan Penerima Potongan UKT Menggunakan Metode TOPSIS.

a) Kelebihan Sistem Pendukung Keputusan Penentuan Penerima Potongan UKT Menggunakan Metode TOPSIS adalah dapat membantu pihak manajemen untuk mengambil keputusan yang objektif.

b) Kekurangan dari Sistem Pendukung Keputusan Penentuan Penerima Potongan UKT Menggunakan Metode TOPSIS ini masih sederhana.

5. User Acceptance Test (UAT)

Tabel dibawah ini merupakan hasil dari tahapan proses pengujian yang dilakukan oleh operator didampingi oleh peneliti. [10]

Tabel 2. User Acceptance Test

\begin{tabular}{|c|l|c|c|c|}
\hline NO & $\begin{array}{l}\text { Aplikasi / } \\
\text { Modul }\end{array}$ & $\begin{array}{c}\text { Jumlah } \\
\text { Pengujian }\end{array}$ & $\begin{array}{c}\text { Jumlah } \\
\text { Tim }\end{array}$ & Hasil \\
\hline 1. & Dashboard & 15 & 1 & Baik \\
\hline 2. & Kriteria & 15 & 1 & Baik \\
\hline 3. & Alternatif & 15 & 1 & Baik \\
\hline 4. & $\begin{array}{l}\text { Perhitungan } \\
\text { Topsis }\end{array}$ & 20 & 1 & Baik \\
\hline 5. & $\begin{array}{l}\text { User } \\
\text { Management }\end{array}$ & 2 & 1 & Baik \\
\hline 6. & User Profile & 2 & 1 & Baik \\
\hline
\end{tabular}

\subsection{Pembahasan}

Setelah Sistem Pendukung Keputusan Penentuan Penerima Potongan UKT Menggunakan Metode TOPSIS 
dirancang kemudian dibangun dan diimplementasikan, sistem ini mampu memberikan informasi untuk membantu pihak manajerial membuat keputusan yang objektif dan efektif.

$$
\text { Aplikasi Sistem Pendukung }
$$

Keputusan Penentuan Penerima Potongan UKT Menggunakan Metode TOPSIS membantu manajerial mempermudah pengambilan keputusan secara cepat.

\section{SIMPULAN}

Dari pemaparan diatas dapat disimpulkan bahwa adanya Sistem Pendukung Keputusan Menggunakan Metode Topsis ini:

a. Dapat digunakan tidak hanya untuk Menentukan Penerima Potong Biaya UKT saja. Tetapi bisa digunakan untuk kebutuhan permasalahan yang lain.

b. Sistem Pendukung Keputusan Menggunakan Metode Topsis dapat membantu Manajerial untuk mendapatkan hasil pilihan yang subyektif.

\section{DAFTAR PUSTAKA}

[1] P. Tinggi, PEDOMAN PELAKSANAAN BANTUAN UKT / SPP MAHASISWA. 2022.

[2] E. Turban, R. Sharda, and D. Delen, Decision Support and Systems
Interoperability, no. September. 2011.

[3] Multi-Criteria Decision Making Methods: A Comparative Study. Baton Rouge, Louisiana, US.A. SPRINGER-SCIENCE+BU:

SPRINGER-SCIENCE+BUSINESS MEDIA B.V.

[4] W. Purbaratri, M. Moedjiono, and M. F. P. Alam, "Selection of the Best Lecturers using the AHP (Analytical Hierarchy Process) and TOPSIS (The Technique for Order of Preference by Similarity to Ideal Solution): Case Study of STMIK Insan Pembangunan," bit-Tech, vol. 1, no. 2, pp. 1-10, 2018, doi: 10.32877/bt.v1i2.38.

[5] B. Unhelkar, Software Engineering With UML. Boca raton, Florida: CRC Press, 1384.

[6] S. Bagui and R. Earp, Database Design Using Entity Relationship Diagrams, vol. 53, no. 9. 2012.

[7] T. . Wilson, Prorgramming For Beginner's. 2015.

[8] H. Bhardwaj, PHP Mysql For Advanced Learning, Third Edit. India: Booksclinic Publishing, 2021.

[9] M. David, "HTML, CSS , B oo tstr a p , J a v a script a nd jQu e ry.”

[10] P. Young, Software testing and analysis: process, principles, and 
techniques, vol. 46, no. 02. 2008 